\title{
Mayer-Rokitansky-Küster-Hauser syndrome
}

INSERM

\section{Source}

INSERM. (1999). Orphanet: an online rare disease and orphan drug data base. MayerRokitansky-Küster-Hauser syndrome. ORPHA:3109

Mayer-Rokitansky-Küster-Hauser (MRKH) syndrome describes a spectrum of Mullerian duct anomalies characterized by congenital aplasia of the uterus and upper $2 / 3$ of the vagina in otherwise phenotypically normal females. It can be classified as either MRKH syndrome type 1 (corresponding to isolated utero-vaginal aplasia) or MRKH syndrome type 2 (utero-vaginal aplasia associated with other malformations) (see these terms). 